\title{
KARAKTERISTIK PENGARUH BIODIESEL DARI LIMBAH SAWIT CAIR TERHADAP UNJUK KERJA MESIN DIESEL EMPAT LANGKAH
}

\author{
${ }^{1}$ Farida Ariani, ${ }^{2}$ Elisabeth Ginting, ${ }^{3}$ Tulus Burhanuddin Sitorus \\ ${ }^{1,3}$ Departemen Teknik Mesin Fakultas Teknik USU - Indonesia \\ ${ }^{2}$ Departemen Teknik Industri Fakultas Teknik USU - Indonesia \\ Jl. Politeknik Kampus USU Medan - 20155, Telp. (061) 8213250
}

tburhanudin@yahoo.com

\begin{abstract}
ABSTRAK
Perkembangan dunia industri yang semakin pesat dan kelangkaan akan bahan bakar fosil mendorong dilakukannya penelitian untuk mengembangkan sumber bahan bakar alternatif untuk mengurangi ketergantungan terhadap bahan bakar solar. Pada penelitian ini digunakan bahan bakar alternatif biodiesel POME yang diperoleh dari pengolahan limbah asam lemak sawit melalui proses esterifikasi. Penelitian ini bertujuan untuk mengetahui pengaruh penggunaan campuran solar-biodiesel POME terhadap parameter performansi mesin genset diesel.Variasi bahan bakar yang digunakan solar, B5, B10, B15 dan B20.Hasil penelitian menunjukkan bahwa nilai kalor paling tinggi terdapat pada bahan bakar solar sebesar $43294 \mathrm{~kJ} / \mathrm{kg}$. Dan nilai kalor paling rendah terdapat pada bahan bakar B20 yaitu $34708 \mathrm{~kJ} / \mathrm{kg}$.Dari hasil pengujian di laboratorium diperoleh bahwa daya maksimum terjadi saat mesin menggunakan bahan bakar solar pada putaran mesin $1200 \mathrm{rpm}$ sebesar 445,03 watt. Sedangkan daya minimum diperoleh saat mesin menggunakan bahan bakar B20 pada putaran mesin 700 rpm sebesar 121,84 watt. Untuk nilai konsumsi bahan bakar spesifik minimum diperoleh sebesar $359 \mathrm{gr} / \mathrm{kWh}$ pada pemakaian bahan bakar premium pada putaran mesin $1200 \mathrm{rpm}$ dan konsumsi bahan bakar maksimum diperoleh saat mesin menggunakan bahan bakar B20 sebesar 930,84 pada putaran mesin $700 \mathrm{rpm}$. Besarnya efisiensi termal maksimum sebesar $24 \%$ dengan menggunakan solar untuk putaran mesin $1200 \mathrm{rpm}$ dan nilai efisiensi termal minimum sebesar 11,55\% dengan menggunakan bahan bakar B20 pada putaran mesin $700 \mathrm{rpm}$.Kondisi tingkat kekabutan atau opasitas emisi gas buang paling tinggi terjadi saat mesin menggunakan bahan bakar solar dan minimum saat mesin menggunakan bahan bakar B20.
\end{abstract}

Kata kunci :biodiesel limbah sawit, performansi mesin

\section{PENDAHULUAN}

Keterbatasan produksi minyak dan cadangan minyak mentah dunia khususnya di Indonesia sebagai sumber bahan baku yang terus menurun,diperlukan bahan bakar alternatif yang suplainya kontinu dan ramah lingkungan. Sumber bahan baku untuk bahan bakar pengganti minyak solar sebenarnya cukup bervariasi antara lain biji jarak, minyak goreng bekas, mentega dan minyak CPO (crude palm oil). Sebagai salah satu negara penghasil CPO terbesar dunia, Indonesia juga telah mengembangkan produk biodiesel dari minyak sawit (palm biodiesel).

Hal yang menjadi permasalahan sehingga menarik untuk diteliti yaitupengembangan biodiesel memiliki prospek yang sangat baik namun terkendala oleh ketersediaan akan bahan baku yang cukup banyak, disebabkan kebutuhan terhadap CPO harus bersaing antara untuk penggunaan pangan dan bahan bakar.Oleh karena itu diperlukan alternatif bahan baku untuk biodiesel yang tidak mengganggu suplai pangan. Disamping itu selama ini bahan bakar biodiesel limbah sawit cair POME digunakan untuk mesin diesel putaran rendah yaitu mesin diesel yang beroperasi di bawah $1000 \mathrm{rpm}$ dan ini hanya terdapat pada mesin diesel yang terdapat di pembangkit listrik tenaga diesel. Hal inilah yang menjadi tantangan bagi peneliti untuk 
Karakteristik Pengaruh Biodiesel Dari Limbah Sawit Cair Terhadap Unjuk Kerja Mesin

Diesel Empat Langkah

mengaplikasikan bahan bakar tersebut pada mesin diesel putaran tinggi seperti mesin diesel untuk transportasi, mesin genset atau mesin stasioner di laboratorium.

Dengan melakukan variasi campuran solar-biodiesel maka akan didapatkan unjuk kerja terbaik dan kendala-kendala yang timbul sehingga akan diperoleh suatu rekomendasi yang berguna untuk para peneliti di bidang biodiesel.Penelitian yang menggunakan bahan bakar alternatif khususnya untuk mesin diesel selama ini telah dilakukan oleh beberapa peneliti di bidang energi. Namun penelitian yang menggunakan bahan bakar dari limbah sawit untuk mesin diesel putaran tinggi dapat dikatakan masih jarang dilakukan. Penelitian ini bertujuan untukmengetahui pengaruh pemakaian biodiesel limbah sawit cair POME terhadap unjuk kerja mesin diesel empat langkah.

\section{KAJIAN TEORITIS}

Biodiesel dari Limbah Sawit

Biodiesel merupakan bahan bakar yang digunakan sebagai subsitusi bahan bakar solar yang cadangannya sudah semakin menipis.Salah satu sumber bahan baku biodiesel yang masih jarang dimanfaatkan adalah limbah sawit cair POME. POME (acid waste oil) merupakan sumber bahan baku yang cukup penting yaitu limbah cair yang berasal dari operasional pabrik kelapa sawit. Besarnya POME yang dihasilkan sekitar $1-1,5 \%$ dari produksi CPO.Di Indonesia hasil pengolahan bahan bakar ini dinamakan nusafuel yang diproduksi oleh PT. Nusantara Bioenergy Investama.Bahan bakarnusafuel yang berasal dari limbah sawit cair POME memiliki spesifikasi seperti berikut :

Tabel 1. Spesifikasi biodiesel POME [1]

\begin{tabular}{|l|c|c|}
\hline \multicolumn{1}{|c|}{ Parameter } & Unit & Limit \\
\hline Density & $\mathrm{kg} / \mathrm{m} 3$ & $890-910$ \\
\hline Flash point & $\mathrm{C}$ & $>100$ \\
\hline Coke residue & $\%$ & $<0.4$ \\
\hline
\end{tabular}

\begin{tabular}{|l|c|c|} 
Sediment content & Ppm & $<200$ \\
\hline Phoshporus content & $\mathrm{Ppm}$ & $<10$ \\
\hline Viscosity @ 60 C & $\mathrm{cp}$ & $<10$ \\
\hline Ash content & $\%$ & $<0.01$ \\
\hline Water content & $\%$ & $<0.2$ \\
\hline Acidity & $\mathrm{mg} \mathrm{KOH} / \mathrm{g}$ & $4 \mathrm{max}$ \\
\hline Sulphur content & $\%$ & $<0.05$ \\
\hline Cetane number & & $41 \mathrm{~min}$ \\
\hline $\begin{array}{l}\text { Methylester content } \\
\text { Vegetable Oil }\end{array}$ & \multicolumn{2}{|c|}{ Balance to 100\% } \\
\cline { 2 - 3 }
\end{tabular}

\section{RisetMengenai Biodiesel}

Beberapa penelitian di bidang bahan bakar biodiesel dapat diuraikan sebagai berikut. Markus [2] dari tim peneliti BPPT melakukan analisa pengaruh campuran bahan bakar solar - minyak jarak pagar pada kinerja motor diesel dan emisi gas buang. Hasil risetnya menyimpulkan bahwa peningkatan persentase minyak jarak pagar di dalam campuran bahan bakar akan menurunkan nilai kalor bahan bakar sehingga konsumsinya meningkat dan makin tinggi persentase minyak jarak pagar di dalam campuran bahan bakar, makin tinggi emisi $\mathrm{CO}_{2}$ dan $\mathrm{NOx}$ di dalam gas buang, tetapi makin rendah emisi HC, $\mathrm{O}_{2}$ dan opasitas emisi gas buang.

Murni [3] (Universitas Diponegoro)melakukan kajian eksperimental pengaruh temperatur terhadap viskositas biodiesel minyak sawit dan uji performa pada mesin diesel injeksi langsungputaran konstan. Inti penelitiannya adalah peningkatan konsumsi bahan bakar dan penurunan daya mesin mengakibatkan efisiensi termal menjadi menurun, karena efisiensi termal suatu motor bakar didefinisikan sebagai besarnya pemanfaatan panas yang dihasilkan dari pembakaran bahan bakar menjadi kerja mekanis. Panas atau tenaga yang diberikan oleh bahan bakar dapat diprediksi melalui besarnya konsumsi bahan bakar, sedangkan besar kerja mekanis dapat ditetapkan dari daya mesin yang diukur.Oleh karena itu, harga dari efisiensi termal ini dipengaruhi oleh perubahan daya mesin dan perubahan laju 
Karakteristik Pengaruh Biodiesel Dari Limbah Sawit Cair Terhadap Unjuk Kerja Mesin

Diesel Empat Langkah

bahan bakar yang dikonsumsi oleh mesin tersebut.

Peneliti lain ialah I Wayan Susila[4] yang menganalisa kinerja mesin diesel memakai bahan bakar biodiesel biji karet dan analisa emisi gas buang yang menyimpulkan bahwa bahan bakar B-10 menghasilkan kinerja mesin terbaik pada putaran $2550 \mathrm{rpm}$. Pada putaran ini diperoleh daya maksimum sebesar 36,95 PS, konsumsi bahan bakar spesifik terendah sebesar 0,256 $\mathrm{kg} /(\mathrm{PS} . j \mathrm{am})$, efisiensi termal58,44\%, kandungan $\mathrm{CO}$ terkecil sebesar $0,4 \%$, dan opasitas gas buang 58,6\% HSU memenuhi Peraturan Menteri Negara Lingkungan Hidup Nomor 5 tahun 2006, dan tidak perlu memodifikasi mesin. Jika dibandingkan dengan solar murni (B-0), B-10 lebih baik dari pada B-0 karena pada kondisi optimum menghasilkan kenaikan daya sebesar 1,8\%, konsumsi bahan bakar spesifik sama 0,256 kg/(PS.jam), efesiensi termal naik $2,4 \%$, kadar $\mathrm{CO}$ gas buang turun $80 \%$, serta $\mathrm{CO}_{2}$ turun $55 \%$.

Dutra, L. M dkk [5] menganalisa performansi mesin diesel dan emisi gas buang dengan campuran biodiesel dari metal dan etil ester dan menyimpulkan konsumsi bahan bakar spesifik berhubungan langsung dengan nilai kalor bahan bakar dimana semakin tinggi nilai kalor bahan bakar maka konsumsi bahan bakar semakin kecil dan sebaliknya. Jadi berdasarkan penelitiannya bahwa pada pengujian performansi, parameter konsumsi bahan bakar paling sedikit adalah saat mesin diesel menggunakan bahan bakar campuran solar dan biodiesel $20 \%$ (B20) diikuti oleh B50 dan B100.

Sedangkan P. Suresh Kumar dkk [6] melakukanpengujian menggunakan mesin diesel indirect injectionmenyatakan bahwa dengan memvariasikan tekanan injeksi dan sudut injeksi bahan bakar maka akan mempengaruhi emisi gas buang yang dihasilkan oleh mesin tersebut. Namun secara umum dapat disimpulkan bahwa terjadi pengurangan emisi gas buang untuk

$\mathrm{CO}$, NOx dan $\mathrm{HC}$ bila menggunakan bahan bakar jatropa dibandingkan bila menggunakan bahan bakar solar dengan kondisi tekanan dan sudut injeksi bahan bakar yang sama.

\section{Parameter Unjuk Kerja Mesin}

Beberapa parameter umum dari performansi mesin utama dapat dijelaskan sebagai berikut $[7,8]$.

\section{Daya Mesin}

Daya mesin dipengaruhi oleh putaran mesin dan torsi yang dihasilkan mesin. Namun yang digunakan dalam praktek di lapangan adalah daya poros. Daya poros atau daya efektif merupakan daya yang dihasilkan suatu mesin pada poros keluarannya atau biasa dikenal dengan brake horse power yang dihitung dengan persamaan :

$$
\dot{W}=\frac{2 \pi \times N \times \tau}{60}
$$

\section{Konsumsi Bahan Bakar Spesifik}

Dapat dikatakan bahwa secara tidak langsung konsumsi bahan bakar spesifik merupakan indikasi efisiensi mesin dalam menghasilkan daya dari pembakaran bahan bakar.Besarnya konsumsi bahan bakar spesifik dapat didefinisikan sebagai berikut :

$$
s f c=\frac{m_{f}}{\dot{W}}
$$

\section{Efisiensi Termal}

Besarnya efisiensi termal suatu mesin dapat didefenisikan sebagai rasio energi keluaran dengan energi kimia yang masuk yang dimiliki bahan bakar dalam bentuk bahan bakar yang dihisap ke dalam ruang bakar dan dapat didefinisikan sebagai :

$$
\eta_{t}=\frac{\dot{W}}{\dot{m}_{f} \times Q_{H V} \times \eta_{c}}
$$

Dalam penerapannya, besarnya pencampuran minyak biodiesel dengan minyak solar dianjurkan kurang dari $20 \%$ karena pertimbangan teknis terkait dengan pengaruh karakteristik fisika-kimia 
Karakteristik Pengaruh Biodiesel Dari Limbah Sawit Cair Terhadap Unjuk Kerja Mesin

Diesel Empat Langkah

campuran bahan bakar terhadap kondisi mesin. Bila minyak solar dicampur dengan biodiesel maka menjadikan campuran bahan bakar tersebut bersifat lebih asam sehingga menyebabkan seal dan karet pada mesin menjadi mengembang sehingga memungkinkan terjadinya kebocorankebocoran yang tidak diharapkan. Hal ini mengakibatkan performansi mesin menjadi berkurang [9].

\section{METODOLOGI PENELITIAN Tempat Penelitian}

Penelitian ini dilaksanakan di Laboratorium Prestasi MesinDepartemen Teknik Mesin Fakultas Teknik Universitas Sumatera Utara, selama tujuh bulan.

\section{Bahan dan Alat}

a. Bahan

Bahan yang digunakan pada penelitian ini adalah :

○ Minyak solar

- Campuran minyak limbah sawit cair POME (biodiesel) dan solar dengan perbandingan :

- Solar 95\% + biodiesel POME 5\% (disebut B5)

- Solar 90\% + biodiesel POME 10\% (disebut B10)

- Solar 85\% + biodiesel POME 15\% (disebut B15)

- Solar $80 \%$ + biodiesel POME 20\% (disebut B20)

b. Alat ukur yang digunakan
- Bomb calorimeter
- Timbangan
- Alat uji emisi gas buang "auto gas analyzer"
- Tachometer

c. Mesin genset dengan spesifikasi :

Tipe: diesel, 1 silinder, 4 langkah

Diameter silinder : $75 \mathrm{~mm}$

Langkah silinder $\quad: 80 \mathrm{~mm}$

Volumesilinder $: 353 \mathrm{cc}$

Rasio kompresi : 22

Berat netto $\quad: 80 \mathrm{~kg}$

\section{Skema Pengujian}

Skema pengujian yang dilakukan dilaboratorium dapat dilihat pada gambar 1.Mesin diesel empat langkah yang telah disiapkan lalu dihubungkan dengan alat ukur dan alat pendukung. Alat ukur yang digunakan yaitu tachometer untuk mengukur putaran poros mesin dan multitester untuk mengetahui daya yang dihasilkan mesin. Kemudian pada bagian ujung knalpot juga ditempatkan alat ukur emisi gas buang. Pelaksanaan pengujian dilakukan dengan memvariasikan jenis campuran bahan bakar dan variasi putaran mesin serta beban konstan berupa bola lampu pijar 800 watt.

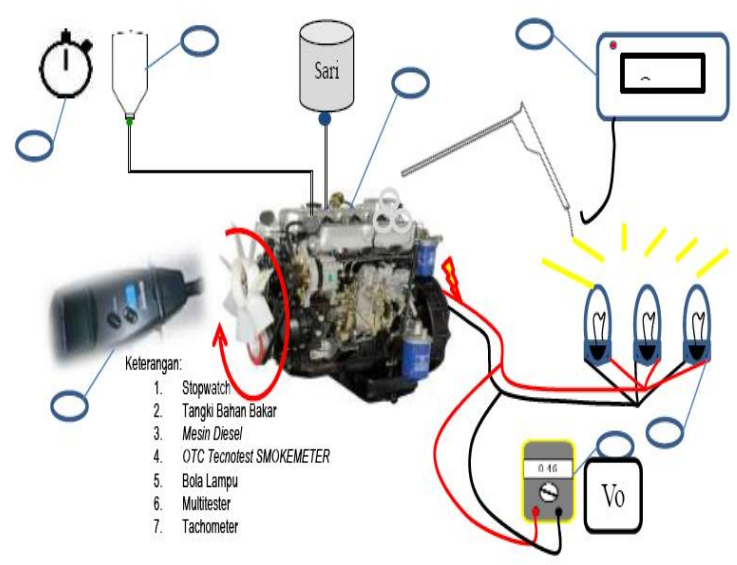

Gambar 1. Skemapengujian

\section{HASIL DAN PEMBAHASAN \\ Nilai Kalor Bahan Bakar}

Dari hasil pengujian di laboratorium menggunakan peralatan calorimeter bomb diperoleh bahwa nilai kalor paling tinggi terdapat pada bahan bakar solar sebesar $43294 \mathrm{~kJ} / \mathrm{kg}$. Nilai kalor paling rendah terdapat pada bahan bakar B20 yaitu $34708 \mathrm{~kJ} / \mathrm{kg}$. Nilai kalor bahan bakar menunjukkan energi yang dihasilkan pada saat proses pembakaran bahan bakar per satuan massanya dimana nilai kalor dipengaruhi oleh komposisi penyusun bahan bakar tersebut. Tampak dari tabellbahwa semakin tinggi kadar biodiesel POME dalam campuran bahan bakar maka nilai kalor bahan bakar semakin rendah. Hal ini disebabkan karena adanya oksigen dalam struktur biodiesel,

\footnotetext{
${ }^{1}$ Farida Ariani, ${ }^{2}$ Elisabeth Ginting, ${ }^{3}$ Tulus Burhanuddin Sitorus. Dosen USU
} 
Karakteristik Pengaruh Biodiesel Dari Limbah Sawit Cair Terhadap Unjuk Kerja Mesin

Diesel Empat Langkah

sehingga untuk mendapatkan energi yang

sama maka jumlah bahan bakar biodiesel yang diperlukan menjadi lebih besar.

Tabel 2. Hasil pengujian nilai kalor bahan bakar

\begin{tabular}{|l|c|}
\hline \multicolumn{1}{|c|}{ Bahan Bakar } & Nilai Kalor $(\mathbf{k J} / \mathbf{k g})$ \\
\hline Solar & 43294 \\
\hline B5 & 41068 \\
\hline B10 & 38418 \\
\hline B15 & 36722 \\
\hline B20 & 34708 \\
\hline
\end{tabular}

\section{Daya Mesin}

Seperti dijelaskan pada bagian sebelumnya bahwa pengujian dilakukan dengan pembebanan konstan sebesar 800 watt dengan menggunakan delapan bola lampu pijar yang masing-masing 100 watt.Dari hasil pengujian di laboratorium diperoleh bahwa daya maksimum terjadi saat mesin menggunakan bahan bakar solar pada putaran mesin $1200 \mathrm{rpm}$ sebesar 445,03 watt. Sedangkan daya minimum diperoleh saat mesin menggunakan bahan bakar B20 pada putaran mesin $700 \mathrm{rpm}$ sebesar 121,84 watt. Tampak dari hasil pengujian mesin bahwa peningkatan komposisi biodiesel pada campuran bahan bakar mempengaruhi daya mesin yang dihasilkan oleh mesin. Hal ini sangat dipengaruhi oleh kandungan nilai kalor dari bahan bakar yang dipergunakan. Semakin tinggi nilai kalor bahan bakar maka energi panas yang dihasilkan semakin besar sehingga berpengaruh terhadap daya yang dihasilkan.Faktor lain yang memungkinkan terjadinya penurunan daya mesin pada pemakaian B5 hinggaB20 adalah karena kurang tepatnya setting timing injection, hal ini disebabkan bilangan setana biodiesel lebih tinggi dari solar sehingga diperlukan ignition delay yang lebih pendek. Oleh karena itudiperlukan upaya memajukan timing injection mendapatkan daya optimum.

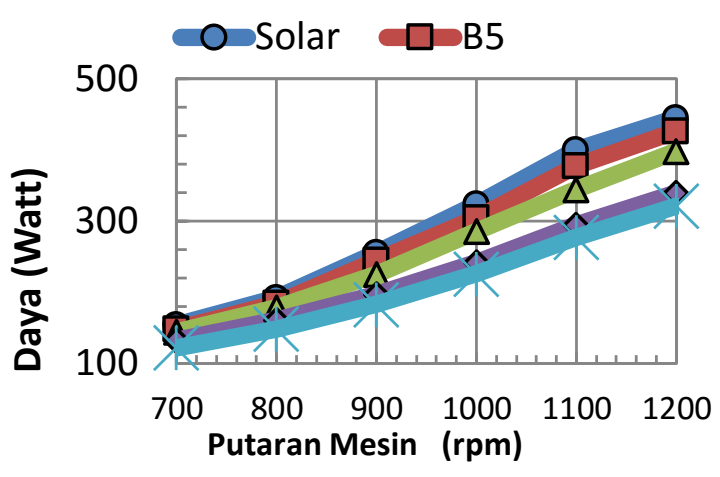

Gambar 2. Daya vs putaran mesin

\section{Konsumsi Bahan Bakar Spesifik}

Dari hasil pengujian didapatkan nilai konsumsi bahan bakar spesifik minimum sebesar $359 \mathrm{gr} / \mathrm{kWh}$ pada pemakaian bahan bakar premium pada putaran mesin 1200 rpm. Sedangkan konsumsi bahan bakar maksimum diperoleh saat mesin menggunakan bahan bakar B20 sebesar 930,84 pada putaran mesin $700 \mathrm{rpm}$.

Dapat disimpulkan bahwa semakin besar kandungan biodiesel di dalam campuran bahan bakar maka semakin besar konsumsi bahan bakar spesifik yang terjadi.Hal ini disebabkan nilai kalor B5 hingga B20 lebih rendah dari solar akibat oksigen dalam biodiesel POME menyebabkan campuran udara-bahan bakar menjadi lebih miskin (lean mixture) sehingga untuk mendapatkan kinerja diinginkan maka campuran udara-bahan bakar harus dibuat lebih kaya (rich mixture). Kondisi ini membuat bahan bakar campuran yang dibutuhkan lebih banyak dibandingkan bila menggunakan bahan bakar solar.

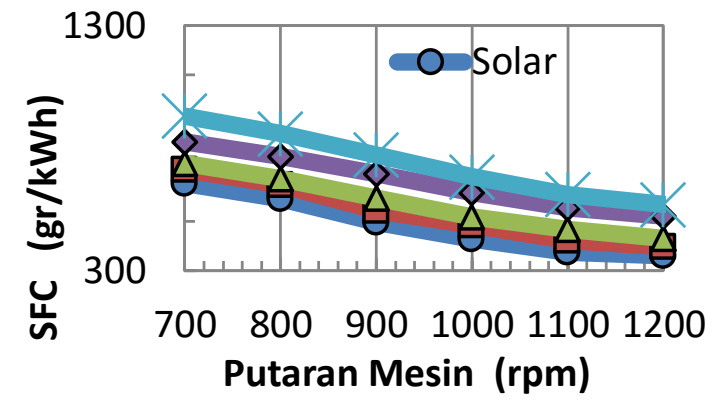

Gambar 3. SFC vs putaran mesin

\footnotetext{
${ }^{1}$ Farida Ariani, ${ }^{2}$ Elisabeth Ginting, ${ }^{3}$ Tulus Burhanuddin Sitorus. Dosen USU
} 
Karakteristik Pengaruh Biodiesel Dari Limbah Sawit Cair Terhadap Unjuk Kerja Mesin

Diesel Empat Langkah

\section{Efisiensi Termal}

Efisiensi termal yang diperoleh dari hasil perhitungan berdasarkan data pengujian dilaboratorium diperoleh seperti tampak pada gambar 4 di bawah ini.

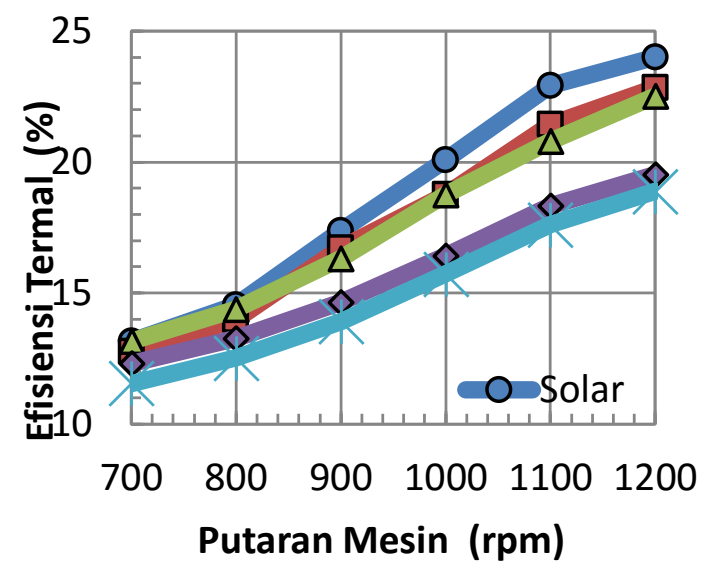

Gambar 4. Efisiensi termal vs putaran mesin

Hasil pengujian menunjukkan bahwa harga efisiensi termal maksimum sebesar $24 \%$ dengan menggunakan solar untuk putaran mesin $1200 \mathrm{rpm}$ dan nilai efisiensi termal minimum didapatkan sebesar $11,55 \%$ dengan menggunakan bahan bakar B20 pada putaran mesin 700 rpm.Sesuai dengan persamaan yang digunakan untuk menghitung efisiensi termal bahwa efisiensi termal dari motor bakar dipengaruhi oleh beberapa variabel seperti daya mesin, laju aliran bahan bakar ke ruang bakar dan nilai kalor bahan bakar yang digunakan. Ketiga parameter tersebut secara simultan mempengaruhi pencapaian efisiensi termal suatu mesin.

\section{Kondisi Injektor}

Pada pengujian ini juga dilakukan pengamatan terhadap kondisi injektor akibat proses pembakaran yang terjadi di dalam ruang bakar saat menggunakan bahan bakar solar dan saat menggunakan campuran bahan bakar solar - biodiesel POME. Seperti diketahui bahwa injektorberfungsi mengabutkan bahan bakar sebelum masuk ruang bakarProses pengabutan bahan bakar tersebut

cukupberpengaruh terhadap proses pembakaran yang terjadi di ruang bakar. Semakin kabut bahan bakar tersebut, maka pembakaran yang terjadi akan semakin mendekati sempurna dan mempengaruhi efisiensi termal yang diperoleh mesin. Kondisi injektor setelah pengujian dapat dilihat pada gambar berikut.

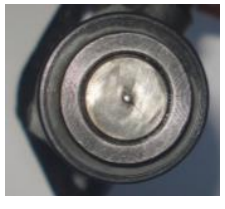

(a)

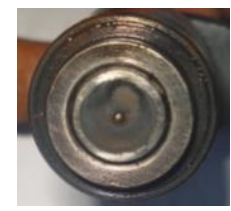

(d)

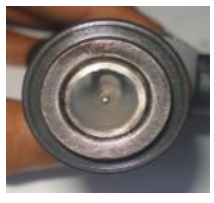

(b)

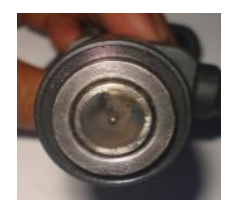

(e)

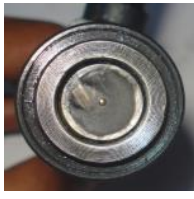

(c)

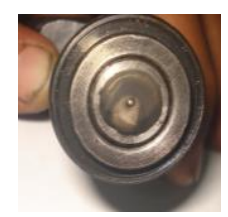

(f)

Gambar 5.

(a)Kondisi injektor sebelum dilakukan Pengujian.

(b) kondisi injektor menggunakan solar

(c) kondisi injektor menggunakan B5

(d) kondisi injektor menggunakan B10

(e) kondisi injektor menggunakan B15

(f) kondisi injektor menggunakan B20

Tampak bahwa kondisi injektor yang belum digunakan (a) memiliki permukaan yang bersih dan tidak memiliki kerak hitam pada permukaannya.Sedangkan untuk kondisi injektor setelah dilakukan pengujian tampak memiliki kerak hitam hasil pembakaran yang menempel pada permukaan injektor. Dapat disimpulkan bahwa sisa kerak hitam paling tebal di permukaan injektor terdapat saat mesin diesel diuji dengan menggunakan bahan bakar solar.Sedangkan kondisi permukaan injektor yang memiliki sisa kerak hitam paling tipis terdapat pada saat pengujian dengan menggunakan bahan bakar B20. Hal ini menandakan bahwa peningkatan konsentrasi biodiesel POME pada campuran bahan bakar membuat proses pembakaran yang terjadi menjadi lebih 
Karakteristik Pengaruh Biodiesel Dari Limbah Sawit Cair Terhadap Unjuk Kerja Mesin

Diesel Empat Langkah

baik jika dibandingkan dengan proses pembakaran dengan bahan bakar solar.

\section{Emisi Gas Buang}

Emisi gas buang yang diteliti adalah tingkat kekabutan atau opasitas (opacity) dari gas buang mesin diesel tersebut.

Tabel 3. Hasil uji emisi gas buang untuk opasitas

\begin{tabular}{|c|c|c|c|c|c|c|}
\hline No & $\begin{array}{c}\text { Bahan } \\
\text { Bakar }\end{array}$ & Uji 1 & Uji 2 & Uji 3 & Uji 4 & $\begin{array}{c}\text { Opasitas } \\
\text { (Rata- } \\
\text { rata) \% }\end{array}$ \\
\hline 1 & Solar & 31.60 & 22.10 & 29.60 & 24.77 & 27.02 \\
\hline 2 & B5 & 28.00 & 20.70 & 24.20 & 23.97 & 24.22 \\
\hline 3 & B10 & 22.40 & 26.40 & 19.60 & 19.07 & 21.87 \\
\hline 4 & B15 & 17.30 & 15.70 & 18.30 & 17.27 & 17.14 \\
\hline 5 & B20 & 11.70 & 20.40 & 13.80 & 17.17 & 15.77 \\
\hline
\end{tabular}

Untuk pengujian uji emisi mesin diperoleh nilai opasitas maksimum pada pemakaian bahan bakar solar sebesar $27,02 \%$. Sementara untuk nilai opasitas minimum terjadi melalui pengujian mesin dengan menggunakan bahan bakar B20 sebesar $15,77 \%$. Penurunan nilai dari opasitas tersebut disebabkan oleh penurunan kadar hidrokarbon dalam bahan bakar yang menandakan bahwa proses pembakaran yang terjadi semakin baik. Semakin tinggi persentase biodiesel POME dalam campuran bahan bakar, maka proses pembakaran yang terjadi semakin baik sehingga nilai opasitas dari gas buang yang dihasilkan semakin kecil.

\section{KESIMPULAN}

1. Dari hasil pengujian di laboratorium dengan menggunakan peralatan calorimeter bomb diperoleh bahwa nilai kalor paling tinggi terdapat pada bahan bakar solar sebesar $43294 \mathrm{~kJ} / \mathrm{kg}$. Dan nilai kalor paling rendah terdapat pada bahan bakar B20 yaitu 34708 $\mathrm{kJ} / \mathrm{kg}$.

2. Daya maksimum terjadi pada saat mesin menggunakan bahan bakar solar dengan putaran mesin $1200 \mathrm{rpm}$ sebesar 445,03 watt. Sedangkan daya minimum diperoleh pada saat mesin menggunakan bahan bakar B20 dengan putaran mesin $700 \mathrm{rpm}$, sebesar 121,84 watt.

3. Nilai konsumsi bahan bakar spesifik minimum sebesar $359 \mathrm{gr} / \mathrm{kWh}$ terjadi pada pemakaian bahan bakar premium dengan putaran mesin $1.200 \mathrm{rpm}$. Sedangkan konsumsi bahan bakar maksimum diperoleh pada saat mesin menggunakan bahan bakar B20 sebesar 930,84dengan putaran mesin $700 \mathrm{rpm}$.

4. Hasil pengujian menunjukkan bahwa harga efisiensi termal maksimum sebesar $24 \%$ dengan menggunakan solar untuk putaran mesin $1.200 \mathrm{rpm}$ dan nilai efisiensi termal minimum didapatkan sebesar $11,55 \%$ dengan menggunakan bahan bakar B20 pada putaran mesin $700 \mathrm{rpm}$.

5. Kondisi tingkat kekabutan atau opasitas emisi gas buang paling tinggi terjadi pada saat mesin menggunakan bahan bakar solar dan minimum saat mesin menggunakan bahan bakar B20.

\section{Daftar Simbol}

$\dot{\mathrm{m}}_{\mathrm{f}}=$ laju aliran bahan bakar ke ruang

bakar $(\mathrm{kg} / \mathrm{s})$

$\mathrm{N}$ = putaran mesin / engine speed (rpm)

$\mathrm{n}=$ siklus langkah / tak

$\mathrm{Q}_{\mathrm{HV}}=$ nilai kalor bahan bakar $(\mathrm{kJ} / \mathrm{kg})$

$\mathrm{Sfc}=$ konsumsi bahan bakar spesifik $(\mathrm{kg} / \mathrm{kWs})$

$\dot{\mathrm{W}}=$ daya poros $(\mathrm{W})$

$\rho_{\mathrm{a}}=$ massa jenis udara pada kondisi sekitar $\left(\mathrm{kg} / \mathrm{m}^{3}\right)$

$\tau=\operatorname{torsi}(\mathrm{Nm})$

$\eta_{\mathrm{t}}=$ efisiensi termal 
Karakteristik Pengaruh Biodiesel Dari Limbah Sawit Cair Terhadap Unjuk Kerja Mesin

Diesel Empat Langkah

\section{DAFTAR PUSTAKA}

1. Buku Panduan PT. Nusantara Bioenergy Investama, 2010.

2. Markus Sumarsono (2008), "Analisa Pengaruh Campuran Bahan Bakar Solar Minyak Jarak Pagar Pada Kinerja Motor Diesel dan Emisi Gas Buang”, Jurnal Teknik Lingkungan ISSN 1441$318 X$.

3. Murni (2010), "Kajian Eksperimental Pengaruh Temperatur Terhadap Viskositas Biodiesel Minyak Sawit dan Uji Performa pada Mesin Diesel Direct Injection Putaran Konstan", Tesis Magister Teknik Mesin Universitas Diponegoro.

4. I Wayan Susila (2010), "Kinerja Mesin Diesel Memakai Bahan Bakar Biodiesel Biji Karet dan Analisa Emisi Gas Buang" Universitas Negeri Surabaya, Jurnal Teknik Mesin Vol. 12, No. 1, April 2010: 43 -50

5. Dutra, L. M. (2009), "Comparative Analysis of Performance and Emissions of An Engine Operating with Palm Oil Methyl and Ethyl Esters and Their Blends with , 20th International Congress of Mechanical Engineering November 15-20, 2009, Gramado, RS, Brazil.

6. P. Suresh Kumar, Ramesh Kumar Donga, P. K. Sahoo (2012), “ Experimental Comparative Study Between Perfromance and Emissions of Jatthropa biodiesel and Diesel Under Varying Injection Pressures, "International Journal of Engineering Sciences \& Emerging Technologies, August 2012, ISSN: 2231 - 6604 Volume 3, Issue 1, pp: 98-112 CIJESET

7. John B. Heywood (1988) "Internal Combustion Engines Fundamentals," Masschussets Institute of Technology.

8. W.W. Pulkrabek (1999), "Engineering Fundamentals of The Internal
Combustion Engine", University of Wisconsin, Prentice Hall New Jersey.

9. Badan Pengkajian dan Penerapan Teknologi (2009),'Outlook Energi Indonesia - Teknologi Energi untuk Mendukung Keamanan Pasokan Energi", Jakarta, BPPT - Press

\footnotetext{
${ }^{1}$ Farida Ariani, ${ }^{2}$ Elisabeth Ginting, ${ }^{3}$ Tulus Burhanuddin Sitorus. Dosen USU
} 